Rosse, F. van, Bruijne, M. de, Suurmond, J., Essink-Bot, M.L., Wagner, C. Language barriers and patient safety risks in hospital care: a mixed methods study. International Journal of Nursing Studies: 2015

\begin{tabular}{|c|c|}
\hline $\begin{array}{l}\text { Postprint } \\
\text { Version }\end{array}$ & 1.0 \\
\hline Journal website & http://www.journalofnursingstudies.com/article/S0020-7489(15)00074-7/abstract \\
\hline Pubmed link & http://www.ncbi.nlm.nih.gov/pubmed/?term=25840899 \\
\hline DOI & 10.1016/j.jijnurstu.2015.03.012 \\
\hline
\end{tabular}

This is a NIVEL certified Post Print, more info at http://www.nivel.eu

\title{
Language barriers and patient safety risks in hospital care. A mixed methods study
}

\author{
FloOR VAN Rosse ${ }^{\mathrm{A}, \mathrm{B},}$, , MARTINE DE BRUIJNE $^{\mathrm{B}}$, JEANINE SUURMOND ${ }^{\mathrm{A}}$, MARIE-LOUISE \\ SSINK-BOT $^{\mathrm{A}}$, CORDULA WAGNER ${ }^{\mathrm{B}, \mathrm{C}}$ \\ ${ }^{a}$ Department of Public Health, Academic Medical Centre, University of Amsterdam, The \\ Netherlands \\ ${ }^{\mathrm{b}}$ Department of Public and Occupational Health, EMGO Institute for Health and Care \\ Research, VU University Medical Center, Amsterdam, The Netherlands \\ ${ }^{c}$ Netherlands Institute for Health Services Research (NIVEL), Utrecht, The Netherlands
}

\begin{abstract}
Introduction: A language barrier has been shown to be a threat for quality of hospital care. International studies highlighted a lack of adequate noticing, reporting, and bridging of a language barrier. However, studies on the link between language proficiency and patient safety are scarce, especially in Europe. The present study investigates patient safety risks due to language barriers during hospitalization, and the way language barriers are detected, reported, and bridged in Dutch hospital care.

Methods: We combined quantitative and qualitative methods in a sample of 576 ethnic minority patients who were hospitalized on 30 wards within four urban hospitals. The nursing and medical records of 17 hospital admissions of patients with language barriers were qualitatively analyzed, and complemented by 12 indepth interviews with care providers and patients and/or their relatives to identify patient safety risks during hospitalization. The medical records of all 576 patients were screened for language barrier reports. The results were compared to patients' self-reported Dutch language proficiency. The policies of wards regarding bridging language barriers were compared with the reported use of interpreters in the medical records.

Results: Situations in hospital care where a language barrier threatened patient safety included daily nursing tasks (i.e. medication administration, pain management, fluid balance management) and patient-physician interaction concerning diagnosis, risk communication and acute situations. In 30\% of the patients that reported a low Dutch proficiency, no language barrier was documented in the patient record. Relatives of patients often functioned as interpreter for them and professional interpreters were hardly used.

Discussion: The present study showed a wide variety of risky situations in hospital care for patients with language barriers. These risks can be reduced by
\end{abstract}


Rosse, F. van, Bruijne, M. de, Suurmond, J., Essink-Bot, M.L., Wagner, C. Language barriers and patient safety risks in hospital care: a mixed methods study. International Journal of Nursing Studies: 2015

adequately bridging the language barrier, which, in the first place, demands adequate detecting and reporting of a language barrier. This is currently not sufficiently done in most Dutch hospitals. Moreover, new solutions to bridge language barriers are needed for situations such as routine safety checks performed by nurses, in which a professional or even informal interpreter is not feasible.

\section{What is already known about the topic?}

-Language barriers can be a threat for patient safety.

-Language proficiency should be noted in patient records.

-Language barriers must preferably bridged with professional interpreters.

\section{What this study adds}

-We identified patient safety risks for patients with inadequate language proficiency in specific daily hospital care situations like fluid balance management and pain control.

- The study shows that professional interpreters are not always feasible to overcome patient safety risks related to language barriers.

-Language barriers are often not adequately reported and bridged in Dutch hospital care.

Existing research has established that language barriers can be a threat for patient safety, language proficiency should be noted down in patient records, and that language barriers should preferably be bridged through the use of professional interpreters.

In this study, we identified patient safety risks for patients with inadequate language proficiency in specific daily hospital care situations like fluid balance management and pain control. We also showed that the use of professional interpreters is not always feasible when trying to overcome patient safety risks related to language barriers. Additionally, we established that language barriers are often not adequately reported and bridged in Dutch hospital care.

\section{INTRODUCTION}

A language barrier, which is a communication barrier resulting from the parties concerned speaking different languages, has been shown to be a threat to the quality of hospital care (Karliner et al., 2007). Patient safety is a prerequisite for good quality of care. We define safe hospital care as care where no harm is caused to patients by not following professional standards or by inadequate healthcare management resulting in adverse events such as misdiagnosis or adverse drug reactions. Patient safety risks are situations that potentially lead to adverse events. Several studies described the link between a language barrier and patient safety and Divi et al. showed that US patients with low English proficiency experienced more adverse events than patients with adequate English proficiency (Divi et al., 2007, Johnstone and Kanitsaki, 2006 and Suurmond et al., 2010). Other studies showed 
Rosse, F. van, Bruijne, M. de, Suurmond, J., Essink-Bot, M.L., Wagner, C. Language barriers and patient safety risks in hospital care: a mixed methods study. International Journal of Nursing Studies: 2015

adverse events associated with language barriers in specific domains in hospital care. For example, Wasserman et al. found that medication errors represented a larger share of adverse events for those patients who had a language barrier compared to those who did not (Wasserman et al., 2014).

Several international studies showed a lack of adequate detecting, reporting, and bridging of a language barrier (Karliner et al., 2007). International guidelines, such as the Joint Commission International, provide guidelines to overcome language barriers in their "Standards for hospitals" (JCIA, 2014). They state that: (1) patient education, follow-up instructions, and informed consent must be given in a language the patient can understand; (2) the hospital should seek to reduce language barriers; and (3) the patient's language must be assessed and noted in the patient record. The main accreditation system for quality of hospital care in the Netherlands does not contain standards explicitly related to language barriers (NIAZ).

Professional interpreters are considered the best bridge for a language barrier in health care (Karliner et al., 2007). Internationally, underuse of interpreters in healthcare was reported (Diamond et al., 2009 and Schenker et al., 2011). A Dutch study convincingly showed underuse of professional interpretation services in general practice and another study using professional interpretation service data also suggests underuse in hospital care (Langendijk-van den Berg et al., 2014 and Meeuwesen and Twilt, 2011). However, evidence on the underuse of professional interpreters in Dutch hospital care is lacking.

A Dutch record review cohort study among 1339 hospitalized patients assessing ethnic inequalities in adverse events in Dutch hospital care enabled us to investigate how language barriers were reported and bridged in Dutch hospital care, and to identify patient safety risks related to language barriers during hospitalization (Diamond et al., 2014 and van Rosse et al., 2012). Since nurses and physicians have different tasks in the care process and play different roles, we analyzed patient safety risks during nursing care and during physician care separately. The following research questions were answered in this study:

1. At which moments during hospitalization do language barriers constitute a risk for patient safety?

2. How are language barriers detected and reported in hospital care?

3. How are language barriers bridged in hospital care? What is the policy and what happens in practice?

\section{METHODS}

This mixed-methods study was embedded in a cohort study to investigate ethnic inequalities in adverse event rates in four Dutch urban hospitals among 1339 hospitalized patients, of whom 576 were patients with an ethnic minority background whose data were used for the present study (Diamond et al., 2014, van Rosse et al., 2012 and van Rosse et al., 2014). Patients were included in the cohort during their hospital admission on one of 30 participating wards (10 of which were surgical and 20 non-surgical), and signed a consent form to review their medical record. Details 
Rosse, F. van, Bruijne, M. de, Suurmond, J., Essink-Bot, M.L., Wagner, C. Language barriers and patient safety risks in hospital care: a mixed methods study. International Journal of Nursing Studies: 2015

on patient inclusion can be found in two other publications (van Rosse et al., 2012 and van Rosse et al., 2014). Data collection took place between December 2010 and February 2013 and is visualized in Fig. 1.

\subsection{Data collection}

\subsubsection{Record review}

The complete patient records of all 576 patients were screened for the bigger cohort study by one of the seven independent, trained nurses who were not working in the hospital where the study took place (Diamond et al., 2014 and van Rosse et al., 2012). For the present analysis the following data were extracted from the records: "Did the record give any impression of the Dutch language proficiency of the patient?” with response options: "No”, "Yes, adequate Dutch language proficiency noted in record", "Yes, intermediate or poor Dutch proficiency noted in record", "Yes, 'no Dutch proficiency' noted in record", or "other". The place where the language proficiency information was found was also recorded (i.e. either in the admission intake form or elsewhere in the patient record). When information about inadequate Dutch proficiency was found, nurses recorded whether the record obtained information about the (other) language that the patient spoke (e.g. Turkish, Arabic). Additionally, the records were screened for bridging of a language barrier. Of all records where a language barrier was reported in the record, nurses answered the question "Which solutions were used?" by choosing one or more of the following answers: "an interpreter was used", "a family member/relative of the patient was involved", and/or "other". When nurses chose "an interpreter", we asked whether this was an interpreter via the telephone or live. The nurses were blinded for the selfassessed language proficiency by the patient.

\subsubsection{Patient questionnaire}

For the same 576 patients, data on self-reported Dutch proficiency were collected by a patient questionnaire, containing items on the patient's ability to understand, speak, write, and read the Dutch language, respectively, each on a 4-point scale ("not at all", “a little”, "sufficiently” and "adequately”, representing scores 1-4). Language proficiency was assessed during hospital admission at inclusion in the larger cohort study, and filled out by the patient himself, or with the help of a researcher and/or help from relatives of patients. Questionnaires were available in Dutch, English, and Turkish. Also, Arabic-, Berber-, and Turkish-speaking research assistants were available (van Rosse et al., 2012). Self-assessment of language proficiency has been shown to be a valid method internationally and nationally (Diamond et al., 2014 and Meeuwesen et al., 2006).

\subsubsection{Qualitative data: interviews and document analysis}

We purposively sampled 17 admissions of patients with low Dutch proficiency, aiming for a heterogeneous sample within the bigger cohort. This means we sampled admissions in all four hospitals, on surgical (3) and non-surgical (14) wards, and of 
Rosse, F. van, Bruijne, M. de, Suurmond, J., Essink-Bot, M.L., Wagner, C. Language barriers and patient safety risks in hospital care: a mixed methods study. International Journal of Nursing Studies: 2015

patients with different ethnic backgrounds (8 Turkish, 6 Moroccan, 1 Ghanaian, 1 Algerian, 1 Pakistani).

We searched for language barrier-related text passages in the nursing and medical records of these admissions. Where record reviewers only screened whether a language barrier (bridge) was reported or not, this qualitative approach aimed at finding patient safety risks through in-depth analysis of the language barrier-related text passages. These data were complemented by seven interviews with care providers who were involved in these specific admissions (two nurses, five physicians) and five interviews with patients and/or relatives. Participants were approached face-to-face, by telephone, or by email, whichever was possible. Two care providers did not participate: one nurse did not respond to an interview invitation, and one physician refused to participate due to lack of time. Interviews were semi-structured and addressed the following topics: (1) the impact of a language barrier on daily practice in hospital care; (2) how the language barrier was bridged; (3) the impact of a language barrier on quality of care. Interviews with healthcare providers always took place in the hospital, at the healthcare provider's office, or another quiet location. Interviews with patients and/or relatives took place at the home of the family members, at the workplace of a family member, during hospital admission at the bedside of the patient, or during an outpatient visit. One interview was conducted by telephone. Interviews took between $30 \mathrm{~min}$ and $2 \mathrm{~h}$. All interviews were carried out by the first author, and were carried out in Dutch. One non-Dutch speaking patient was accompanied by a professional interpreter, and in two interviews family members served as interpreter. Interviews were taped and transcribed verbatim. One physician requested to read the transcript afterwards, which did not lead to any changes. Field notes (e.g. on non-verbal communication, 'off the record' texts, impression of atmosphere, etc.) made after each interview were also used to interpret our results. We stopped sampling cases and planning interviews after we had obtained data saturation, i.e. no new patient safety risks emerged from the data within three consecutive admissions.

\subsubsection{Policy data}

The heads of nurses of all participating wards $(N=30)$ were asked to provide information on their policy of bridging language barriers. The hospitals' policies regarding bridging of language barriers were verified through publicly available channels (e.g. from the communication department).

\subsection{Data analysis}

\subsubsection{Analysis of patient safety risks. Qualitative data - interviews and document analysis}

To answer the first research question, "At which moments during hospitalization do language barriers constitute a risk for patient safety?”, content analysis was used (Graneheim and Lundman, 2004). Qualitative data were grouped into the main codes 'language barrier-related patient safety risks in daily nursing care' and 'language barrier-related patient safety risks in daily physician care’, which were later derived 
Rosse, F. van, Bruijne, M. de, Suurmond, J., Essink-Bot, M.L., Wagner, C. Language barriers and patient safety risks in hospital care: a mixed methods study. International Journal of Nursing Studies: 2015

from the data, and divided into specific sub-codes like 'pain assessment', 'risk communication'. All data were analyzed by the first author and three transcripts of interviews and a random selection of record text passages were independently read by another researcher (JS) to check whether the same themes were derived from the data. The "Consolidated criteria for reporting qualitative research" (COREQ) were used as a reporting guideline (Tong et al., 2007).

\subsubsection{Analysis of language barrier reporting. Quantitative data - record review reports and self-assessed language proficiency}

To answer the second research question regarding reporting language barriers, we used quantitative data. Data were analyzed using SPSS 20. Patient questionnaire data and record review data about language proficiency were linked with the unique patient code and correct linkage was checked using the variables age and sex. Selfassessed language proficiency sumscores were calculated from the patient questionnaires. As each of the four domains could have a score between 1 and 4, sumscores varied from 4 to 16 . Cut-off points were determined based on the distribution of the sumscores, and grouped into 'low or no Dutch proficiency' (scores 4-8), 'moderate Dutch proficiency' (9-14) and 'adequate Dutch proficiency' (15 and 16). We categorized record review results regarding reporting of a language barrier into adequate, moderate and low language proficiency. We visually compared language proficiency based on record review data with patient data using crosstabs. A Chi-square test was performed to determine statistical significance.

\subsubsection{Analysis of language barrier bridging. Record review data and policy data}

To answer our third research question "How are language barriers bridged in hospital care? What is the policy and what happens in practice?", we used three sources of data. Firstly, all answers of head nurses about policies regarding use of interpreters and other ways to bridge language barriers were collated in one document and categorized. Secondly, the frequency of use of professional and informal interpreters noted in de medical records was assessed. Thirdly, we used the qualitative text passages to collect examples of how language barrier bridging was recorded.

\section{RESULTS}

Situations in hospital care where a language barrier threatened patient safety included daily nursing tasks (i.e. medication administration, pain management, fluid balance management) and patient-physician interaction concerning diagnosis, risk communication and acute situations. In $30 \%$ of the patients that reported a low Dutch proficiency, no language barrier was documented in the patient record. Relatives of patients often functioned as interpreter for them and professional interpreters were hardly used. We preset these findings one by one. We will describe each of these findings separately in detail below. 
Rosse, F. van, Bruijne, M. de, Suurmond, J., Essink-Bot, M.L., Wagner, C. Language barriers and patient safety risks in hospital care: a mixed methods study. International Journal of Nursing Studies: 2015

\subsection{Moments during hospitalization where language barriers are a risk for patient safety}

In the presentation of results, we distinguish between nursing tasks and physician tasks.

The first patient safety risk we identified in daily nursing practice was the 'drop-out' of protocollised name- and/or date-of-birth checks during critical care moments like medication administration as illustrated by a nurse in excerpt 1 .

Q1 [Interview with nurse1:”It is protocollised to verify the date of birth during medication rounds, when taking blood, or administration of intravenous medication... those are important things”.

FvR: "So all double-checks..."

N1: “All double-checks are cancelled at that moment”.]

A second daily nursing task where we identified patient safety risks was the fluid balance assessment. When the fluid balance cannot adequately be measured, patient safety risks arise. Adverse outcomes like renal- or heart failure or dehydration can be a result of incorrect fluid balance management. Excerpts 2 and 3 show how language barriers affected both the management and the measurement of a patient's fluid balance.

Q2 [Note from record5: "Patient X does not understand that he must use an urinal, so he uses the bathroom, whereupon we cannot adequately report his fluid balance”]

Q3 [Interview with nurse1: "Sometimes she did not drink at all anymore, and at other times she drank too much”]

Pain management was a third daily nursing task where patient safety risks were identified. When a patient has had surgery, as well as in some other medical situations, nurses assess pain three times a day, usually by means of a visual analog scale. When a language barrier is present, it is harder to explain the pain measurement tool to a patient. Inadequate pain measurement can be risky, and both under- and over- assessment of pain can occur, leading to unnecessary suffering or overuse of pain medication. The examples in excerpts 4 and 5 illustrate the problem of achieving adequate pain assessment.

Q4 [Note in nursing record: Patient suffered from pain, reported 10 on the visual analogue scale. I explained to the patient that 10 was really high. It came across like an 8 to me.]

Q5 [Note in patient record7: Patient appears to be in pain, but he does not report this]

The care before discharge and the follow-up after discharge were also found to be prone to patient safety risk. When care just before and after discharge is continued in 
Rosse, F. van, Bruijne, M. de, Suurmond, J., Essink-Bot, M.L., Wagner, C. Language barriers and patient safety risks in hospital care: a mixed methods study. International Journal of Nursing Studies: 2015

the right way, readmissions will be avoided. The example below describes a risky situation. The hospital guideline stated that every discharged patient was called by a nurse a few days afterwards. A standardized form in the patient record was filled out after this phone call. A green 'check' in the box showed that the patient had been contacted and the phone call had taken place. During qualitative analysis, the researcher found out that a language barrier had been present and no additional actions were initiated by the care provider. The 'after-care phone call' was registered as 'successful'.

Q6: [After-care form in patient record17:

Date: $\mathrm{x}-\mathrm{x}-2012$

Diagnosis: Diabetes Mellitus

Time spent: 1 minute

Patient reached: check, with text field filled out as follows: "patient does not understand me on the phone”.]

All other questions (how does the patient feel, how is the pain going, etc.) were not filled out.

In the next example, excerpt 7, a nurse wrote down in the record that she felt that her patient did not understand that he would be going to a rehabilitation center before being discharged to home. Consultation with a professional interpreter was not considered. The nurse ordered a colleague to get relatives to explain the situation.

Q7: [Note in patient record8: Patient does not seem to understand that he will be going to a rehabilitation center before can go home. In case relatives visit patient tomorrow, please get them to explain this to the patient]

The fifth and last nursing care situation we identified as a potential risk for patient safety involved actions including risk communication. For example, the situation described in excerpt 8.

Q8 [Interview with nurse1: I cannot explain to the patient that she should not get out of bed]

Other examples that we found in records and interviews included: patients who leave their bed before they are advised to are at increased risk of falls, and a patient who did not understand instructions to lie on his side because of a pressure ulcer needed surgery because his ulcer had been aggravated.

\subsection{Physician tasks}

The first physician task where we identified patient safety risks is the diagnosis. A language barrier can lead to a delay in diagnosis or misdiagnosis. The example in 
Rosse, F. van, Bruijne, M. de, Suurmond, J., Essink-Bot, M.L., Wagner, C. Language barriers and patient safety risks in hospital care: a mixed methods study. International Journal of Nursing Studies: 2015

excerpt 9 shows how a language barrier can impede an adequate and timely diagnosis.

Q9 [Note from patient record 7: “Clinical picture hard to interpret because of language barrier”... "both his legs, without neurological paralysis, not specific for 'radicular', but diagnosis cannot be excluded because of language barrier]

Acute situations constituted a second domain where we identified patient safety risks related to language barriers. An interview with a physician revealed a typical example. A patient had to lie down without moving due to excessive bleeding, and the physician was not able to make this explicitly clear to the patient. If the physician had not found someone in the corridor who spoke the same language as the patient, the patient could have died because instructions were not understood.

The third and last domain is similar to the last risk we described in daily nursing care and regards risk communication. Risk communication takes place in care situations such as surgery, including the informed consent procedure. Q10 illustrates the struggles of a physician during risk communication with patients with inadequate Dutch proficiency.

Q10 [Interview with physician10: "For someone who speaks Dutch it's easier to say “No, I don't want that”, than for someone doesn't speak Dutch well[...] In the latter case there is a tendency to impose your will too much. I think the rationale behind that is OK, but people \{care providers \} are not aware that they are taking a risk by doing that.[...]that leads to a tendency to trivialize. We have good intentions with the patient, and we want them to make a well-considered decision. I was steering this patient more than I would do with a Dutch speaking patient”]

Many of the examples above also show that care providers do not feel an urge or responsibility to bridge the language barrier (Q5, Q7). We will return to this later in Section 3.

Summarized: situations in hospital care where a language barrier threatened patient safety included daily nursing tasks (i.e. medication administration, pain management, fluid balance management) and patient-physician interaction concerning diagnosis, risk communication and acute situations.

\subsection{Noticing and reporting a language barrier}

In one of four hospitals included in this study, language proficiency was explicitly listed in the admission intake form. Also, in the case of inadequate Dutch proficiency, the preferred language was adequately filled out for each patient. In the three other hospitals, language proficiency was sometimes explicitly written down, but not in a specific, standardized place in the patient record. However, the presence of language barriers was often implicitly noticeable from the record. Also, in the case of a language barrier, the preferred language was sometimes explicitly, but often implicitly, noticeable from the record. The examples below illustrate the way 
Rosse, F. van, Bruijne, M. de, Suurmond, J., Essink-Bot, M.L., Wagner, C. Language barriers and patient safety risks in hospital care: a mixed methods study. International Journal of Nursing Studies: 2015

language barriers were reported, and illustrate the way record reviewers struggled to find language proficiency information in the record.

Patient record: “Language barrier: ++", the record review nurse assumed that this meant that a language barrier was present. The language spoken by the patient remained unclear.

Patient record: "Patient says 'yes' to everything, but I doubt whether he understands everything”. In this case a potential language barrier was reported in the daily nursing charts. The language spoken by the patient remained unclear.

Text field filled out by review nurse: "The reason for communication problems was not easily discovered. It seems that language plays a role"

Text field filled out by review nurse: "Because of a text passage in the patient record about the wish to watch a certain Dutch TV program, I assumed that the patient spoke Dutch”

Text field filled out by review nurse: "From the discharge letter, communication problems arose, but this was not found in the nursing record"

Text field filled out by review nurse: "Patient was born in Morocco so probably the preferred language is Berber or Arabic"

The quantitative analysis on language barrier reports resulted in a discrepancy between patient-assessed language proficiency and record-reported language proficiency. For six records, record reviewers did not complete the questions on language barriers and thus data were missing. Analysis was carried out with the remaining 570 records with complete data. In 199 records, the language proficiency of the patient was not recorded, while 62 of these 199 patients had self-reported inadequate Dutch proficiency. In the remaining 364 records where language proficiency information was found, often there was a discrepancy between selfreported and care provider-reported language proficiency. Overall, healthcare providers judged language proficiency more positively than the patients themselves. For example: In 24 of 189 records where a recording of adequate Dutch proficiency was found, self-reported Dutch proficiency was low (Table 1).

\section{[TABLE 1]}

In summary, in $30 \%$ of the patients that reported a low Dutch proficiency, no language barrier, nor the preferred language of the patient was documented in the patient record. In three out of four hospitals, language proficiency documentation was not standardized. 
Rosse, F. van, Bruijne, M. de, Suurmond, J., Essink-Bot, M.L., Wagner, C. Language barriers and patient safety risks in hospital care: a mixed methods study. International Journal of Nursing Studies: 2015

\subsection{HOW ARE LANGUAGE BARRIERS BRIDGED IN URBAN HOSPITALS WITH AN ETHNICALLY DIVERSE PATIENT POPULATION?}

\subsubsection{Practice}

In 126 of all 576 records, involvement of relatives/family in communication was reported. In three records, the use of a professional interpreter by telephone was explicitly noted, and in 11 cases, a 'live' interpreter was mentioned. However, record reviewers were not sure whether these interpreters were professionals or not.

In our qualitative analysis we found that care providers left the responsibility for bridging the language barrier to the patient and/or the relatives. The example below shows that care providers think that bridging a language barrier is the patient's own responsibility.

Q11 Note copied from patient record: "Diagnosis: Unclear why patient came to $\mathrm{ER}, \mathrm{PE}$ and additional examination revealed no evidence for cardiac ischemia. Treatment: None. Patient should drink sufficiently and bring an interpreter next time.

Another example is excerpt 7, which was shown before, in which the patient did not seem to understand that he was going to a rehabilitation home. The nurse wrote down 'in case the relatives come....', but there is no alternative written down for the case when no relatives came to visit the patient.

Q7: [Note in patient record8: Patient does not seem to understand that he will be going to a rehabilitation center before he can go home. In case relatives visit patient tomorrow, please get them to explain this to the patient]

In many cases, the care provider did not feel responsible for bridging the language barrier, nor felt an urge to contact a professional interpreter. For example in Q7, where the problem is delegated to another care provider and a successful 'bridge' is dependent on the presence of a family member. No follow-up was reported ("what if a family member was not present?”)

Furthermore, nurses mentioned that for quick, short communications, it is not feasible to call an interpreter each time. Also, we found that consulting a professional interpreter during daily nursing care was sometimes not feasible because of technical limitations, like the lack of adequate telephones in patient rooms, when patients were bedridden.

\subsubsection{Hospital policies}

Three out of four hospitals have an explicit policy document which states that the use of a professional interpreter is encouraged, and paid for by the hospital. In one of those three hospitals, the policy document was circulated to the hospital staff after data collection for the present study. This document also contained information such as "How to consult an interpreter". However, none of the heads of nurses referred to the hospital policy in their response. 
Rosse, F. van, Bruijne, M. de, Suurmond, J., Essink-Bot, M.L., Wagner, C. Language barriers and patient safety risks in hospital care: a mixed methods study. International Journal of Nursing Studies: 2015

\subsubsection{Ward policy}

We had data available on ward policies from 23 of 30 ward managers (77\%). Responses were diverse, and there was no similarity between ward policies within hospitals. 22 wards named interpreters among their policies, 20 named family members, 10 named bilingual personnel. Details can be found in online supplementary file 1.

Most wards named more than one policy and most wards also indicated a certain hierarchy in policies, while others only named one policy. For example,

“In daily practice we communicate with gestures'. When we have to explain things, we use colleagues who speak the same language as the patient, or family members of the patient. Additionally, for important conversations or when we doubt the families' interpreting abilities, we use telephone interpreters.”

"We contact family members of the patient who can speak the Dutch language"

Combining all data sources on bridging language barriers, the use of family members is either named as a policy and also used extensively in daily practice. The use of interpreters is often named in policies but not as often specified in the patient records.

In summary, relatives of patients often functioned as interpreter during hospital care. Professional interpreters seem to have been hardly used. Our results reveal a discrepancy between policy and practice, and also between hospital policies and the policies carried out by wards.

\section{Discussion}

We found a wide variety of patient safety risks related to language barriers during the hospitalization of patients with low Dutch language proficiency. Several high-risk situations were found both in nursing and physician care. We found that language barriers were often not adequately reported in patient records, while our results suggest underuse of professional interpretation services. However, interpretation services cannot always be regarded a practical solution, for instance during short routine medication checks.

We identified potential patient safety risks for patients with inadequate language proficiency, like the abandoning of certain safety checks, difficulties with fluid balance management, and risks during acute situations. Some of these risks were also noted in a US Guideline aimed at improving patient safety systems for patients with limited English proficiency where the following high-risk scenarios were mentioned: medication reconciliation, patient discharge, informed consent, emergency department care, and surgical care (Betancourt et al., 2012). The patient safety risks we found in daily nursing care (i.e. protocolled date-of-birth checks during medication administration, fluid balance management) were not reported earlier, and might be the most difficult to prevent because a professional interpreter is not always 
Rosse, F. van, Bruijne, M. de, Suurmond, J., Essink-Bot, M.L., Wagner, C. Language barriers and patient safety risks in hospital care: a mixed methods study. International Journal of Nursing Studies: 2015

feasible, a point we will come back to later. Another study in the Netherlands also found that a language barrier is a problem during daily nursing tasks, but a relation with patient safety risks was not assessed (Suurmond et al., 2012). For hospitals which are accredited by the Joint Commission International (JCI), reporting of language barriers is common practice (JCIA, 2014). However, most Dutch hospitals are accredited by 'NIAZ', a Dutch quality institute, which has no explicit standards on reporting language barriers. Apart from the factual reporting, correctly judging a language barrier is another problem. In our results, the care providers' assessment was often more optimistic than the patient assessment, which points to an overestimation of patients' language proficiency and thus an underestimation of the actual language barrier.

Finally, bridging a language barrier was often accomplished through the family members of patients, and the use of professional interpreters was not standardized. The reason for the assumed underuse of interpreters was not part of the research questions, but our data suggest a combination of reasons. First, our data showed that care providers sometimes thought that bridging the language barrier was not their responsibility but that of the patient, which has also been shown internationally (Pergert et al., 2007). Second, interpretation through gestures, and making use of relatives was considered adequate. Diamond and colleagues found that the underlying reason for the underuse of interpreters is complicated, and not only due to practical reasons such as time constraints (Diamond et al., 2009). A Dutch study shows that care providers do not consider the language barrier as a problem (Seeleman et al., 2012). A European study among five countries (TRICC) showed, as we did, that official policies are not consistent with daily practice when it comes to bridging language barriers in healthcare (Schenker et al., 2011).

\subsection{STRENGTHS AND LIMITATIONS}

The mixed methods design is a strength of this study. The combination of quantitative and qualitative data provided us both with robust numbers on reporting and bridging of language barriers and insight into the mechanisms of the patient safety risks, concerning what exactly happens during hospital admissions of patients with low Dutch proficiency. The use of different data sources enabled triangulation within the study, supporting internal validity of the results. Although a potential limitation is the small number of cases sampled for the qualitative part of this study and the small number of interviews, the data revealed no new patient safety risks and therefore we presumed data saturation. While an interrater reliability analysis of reporting and bridging language barriers would have strengthened our conclusions, it is unlikely that two record review nurses would find widely diverging results, as they were instructed thoroughly before the study started. Another potential limitation is that we only have data from four Dutch hospitals, and thus we cannot generalize the results regarding reporting and bridging a language barrier to Dutch hospital care in general. However, the four hospitals in our sample are a good representation of Dutch urban hospitals with an ethnically diverse patient population. Although the results regarding reporting and bridging of language barriers will not be internationally generalizable, the findings around patient safety risks are generalizable to each healthcare setting throughout the world. 
Rosse, F. van, Bruijne, M. de, Suurmond, J., Essink-Bot, M.L., Wagner, C. Language barriers and patient safety risks in hospital care: a mixed methods study. International Journal of Nursing Studies: 2015

\subsection{IMPLICATIONS FOR PRACTICE AND POLICY}

Adequate reporting is the first step toward adequately bridging language barriers and thus eliminating patient safety risks. In accordance with the JCI standards, we recommend that all hospitals have a standardized way of reporting a language barrier in their patient records that indicates both the presence of a language barrier and the preferred language. The next step is successful and adequate bridging of a language barrier, which should preferably be done by professional interpretation services.

However, for the daily nursing tasks which are frequent and often quick (pain assessment, fluid balance management and date-of-birth safety checks) the consultation of a professional interpreter is not feasible, and sometimes neither is an ad hoc interpreter. Another solution is therefore necessary if we wish to eliminate patient safety risks. In the era of digital tools, one could think of technical help with animations or spoken instructions in the patient's own language on a 'tablet' provided by the nurse to the patient.

In other cases, which are usually not urgent, or not on a daily basis, and often planned - like history taking, diagnosis, risk communication before surgery professional interpreters should be used. Professionally trained interpreters have been proved to provide better translations and cause less technical errors than nonprofessional interpreters like relatives (Karliner et al., 2007). Consequently, the use of interpreters should be 'usual daily practice', which should (technically) be made available by hospital and ward management (i.e. education, availability of suitable telephones, knowledge, and skills on how to use the interpreter service, etc.), which is the case in some of the participating hospitals. Nevertheless, use of the services by care providers is limited.

In the Netherlands, theoretically there is an opportunity to consult professional interpreters, but their availability does not guarantee their use (Bischoff and Hudelson, 2010, Schenker et al., 2011 and Seeleman et al., 2012). As long as care providers do not know how to use them effectively, they will not improve patient care. Ikram et al. developed an e-learning module focusing on the effective bridging of a language barrier using professional interpreters (Ikram et al., 2014). Similar recommendations were recently proposed in a US study concluding that trained professional interpreters can prevent medical error and thus enhance patient safety (Vander Wielen et al., 2014).

Also, all hospital standards should contain elements on reporting and bridging language barriers like the JCI standards. However, JCI does not audit the actual interpreter use (JCIA, 2014).

\section{CONCLUSION}

The present study showed a wide variety of patient safety risks in hospital care for patients with language barriers. These risks can be reduced by adequately bridging the language barrier which, in the first place, asks for adequate detecting and reporting of a language barrier. This is currently not sufficiently done in most Dutch 
Rosse, F. van, Bruijne, M. de, Suurmond, J., Essink-Bot, M.L., Wagner, C. Language barriers and patient safety risks in hospital care: a mixed methods study. International Journal of Nursing Studies: 2015

hospitals. Moreover, new solutions to bridge language barriers are needed for nivel situations in which a professional or even informal interpreter is not feasible, such as routine safety checks performed by nurses.

\section{Conflict of interest}

The authors report no conflicts of interest.

\section{Funding}

Funding by the Dutch Ministry of Health, Welfare, and Sports.

\section{Ethical apporval}

Ethical apporval by medical ethical committees of all participating hospitals.

\section{Acknowledgments}

This study was funded by the Dutch Ministry of Health, Welfare, and Sport. The authors would like to thank Ebru Ertekin for transcribing interviews.

\section{APPENDIX A. SUPPLEMENTARY DATA}

The following are the supplementary data to this article:

\section{REFERENCES}

1. J.R. Betancourt, M.R. Renfrew, A.R. Green, L. Lopez, M. Wasserman. Improving Patient Safety Systems for Patients with Limited English Proficiency: A Guide for Hospitals. Agency for Healthcare Research and Quality, Rockville, MD (2012, July) (AHRQ Publication No. 12-0041, September 2012)

2. A. Bischoff, P. Hudelson. Communicating with foreign language-speaking patients: is access to professional interpreters enough? J. Travel Med., 17 (2010), pp. 15-20

3. L.C. Diamond, Y. Schenker, L. Curry, E.H. Bradley, A. Fernandez. Getting by: underuse of interpreters by resident physicians.J. Gen. Intern. Med., 24 (2009), pp. 256-262

4. L. Diamond, S. Chung, W. Ferguson, J. Gonzalez, E.A. Jacobs, F. Gany. Relationship between self-assessed and tested non-English-language proficiency among primary care providers.Med. Care, 52 (2014), pp. 435-438

5. C. Divi, R.G. Koss, S.P. Schmaltz, J.M. Loeb. Language proficiency and adverse events in US hospitals: a pilot study. Int. J. Qual. Health Care, 19 (2007), pp. 60-67

6. U.H. Graneheim, B. Lundman. Qualitative content analysis in nursing research: concepts, procedures and measures to achieve trustworthiness. Nurse Educ. Today, 24 (2) (2004), pp. 105-112

7. U.Z. Ikram, M.L. Essink-Bot, J. Suurmond. How we developed an effective elearning module for medical students on using professional interpreters. Med. Teach. (August (11)) (2014), pp. 1-6

8. JClA, 2014 Joint Commission International Accreditation Standards for Hospitals. (5th ed.) (2014)

9. M.J. Johnstone, O. Kanitsaki. Culture, language, and patient safety: making the link 10. Int. J. Qual. Health Care, 18 (2006), pp. 383-388 
Rosse, F. van, Bruijne, M. de, Suurmond, J., Essink-Bot, M.L., Wagner, C. Language barriers and patient safety risks in hospital care: a mixed methods study. International Journal of Nursing Studies: 2015

11. L.S. Karliner, E.A. Jacobs, A.H. Chen, S. Mutha. Do professional interpreters improve clinical care for patients with limited English proficiency? A systematic review of the literature. Health Serv. Res., 42 (2) (2007), pp. 727-754.

12. Langendijk-van den Berg, P. Verdonk, T. Abma. De professionele tolk verdwijnt: kwaliteit onder druk. Ned Tijdschr Geneeskd, 158 (2014), p. A7702 (in Dutch)

13. L. Meeuwesen, S. Twilt. If You Don't Understand What I Mean....": Interpreting in Health and Social Care. Centre for Social Policy and Intervention Studies, Utrecht (2011) www.tricc.eu

14. L. Meeuwesen, J.A.M. Harmsen, R.M.D. Bernsen, M.A. Bruijnzeels. Do Dutch doctors communicate differently with immigrant patients than with Dutch patients? Soc. Sci. Med., 63 (2006), pp. 2407-2417

15. NIAZ www.niaz.nl. Pergert et al., 2007

16. P. Pergert, S. Ekblad, K. Enskär, O. Björk. Obstacles to transcultural caring relationships: experiences of health care staff in pediatric oncology. J. Pediatr. Oncol. Nurs., 24 (2007), pp. 314-328

17. Y. Schenker, E.J. Perez-Stable, D. Nickleach, L.S. Karliner. Patterns of Interpreter use for hospitalized patients with limited English proficiency. J. Gen. Intern. Med., 26 (2011), pp. 712-717

18. M.C. Seeleman, K. Stronks, W. van Aalderen, M.L. Essink-Bot. Deficiencies in culturally competent asthma care for ethnic minority children: a qualitative assessment among care providers. BMC Pediatr., 12 (2012), p. 47

19. J. Suurmond, E. Uiters, M.C. de Bruijne, K. Stronks, M.-L. Essink-Bot. Explaining ethnic disparities in patient safety: a qualitative analysis. Am. J. Public Health, 100 (S1) (2010), pp. S113-S117 http://dx.doi.org.proxy.library.uu.nl/10.2105/AJPH.2009.167064

20. J. Suurmond, J. Dokter, N. Van Loey, M.L. Essink-Bot. Issues to address in burn care for ethnic minority children: a qualitative study of the experiences of health care staff.Burns, 38 (August (5)) (2012), pp. 730-737

21. Tong, P. Sainsbury, J. Craig. Consolidated criteria for reporting qualitative research (COREQ): a 32-item checklist for interviews and focus groups. Int. J. Qual. Health Care, 19 (6) (2007), pp. 349-357

22. F. van Rosse, M.C. de Bruijne, C. Wagner, K. Stronks, M.L. Essink-Bot. Design of a prospective cohort study to assess ethnic inequalities in patient safety in hospital care using mixed methods. BMC Health Serv. Res., December (12) (2012), p. 450 http://dx.doi.org.proxy.library.uu.nl/10.1186/1472-6963-12-450

23. F. van Rosse, M.L. Essink-Bot, K. Stonks, M.C. de Bruijne, C. Wagner. Ethnic minority patients not at increased risk of adverse events during hospitalisation in urban hospitals in the Netherlands: results of a prospective observational study. BMJ Open, 4 (2014), p. e005527 http://dx.doi.org.proxy.library.uu.nl/10.1136/bmjopen2014-005527

24. L.M. Vander Wielen, A.S. Enurah, H.Y. Rho, D.R. Nagarkatti-Gude, P. MichelsenKing, S.H. Crossman, A.A. Vanderbilt. Medical interpreters: improvements to address access, equity, and quality of care for limited-English-proficient patients. Acad. Med., 89 (10) (2014), pp. 1324-1327

25. M. Wasserman, M.R. Renfrew, A.R. Green, L. Lopez, A. Tan-McGrory, C. Brach, J.R. Betancourt. Identifying and preventing medical errors in patients with limited English proficiency: key findings and tools for the field. J. Healthc. Qual., 36 (3) (2014), pp. 5-16 
Rosse, F. van, Bruijne, M. de, Suurmond, J., Essink-Bot, M.L., Wagner, C. Language barriers and patient safety risks in hospital care: a mixed methods study. International Journal of

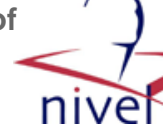

\section{TABLES}

Table 1. Self-reported Dutch proficiency versus Dutch proficiency reported in patient record.

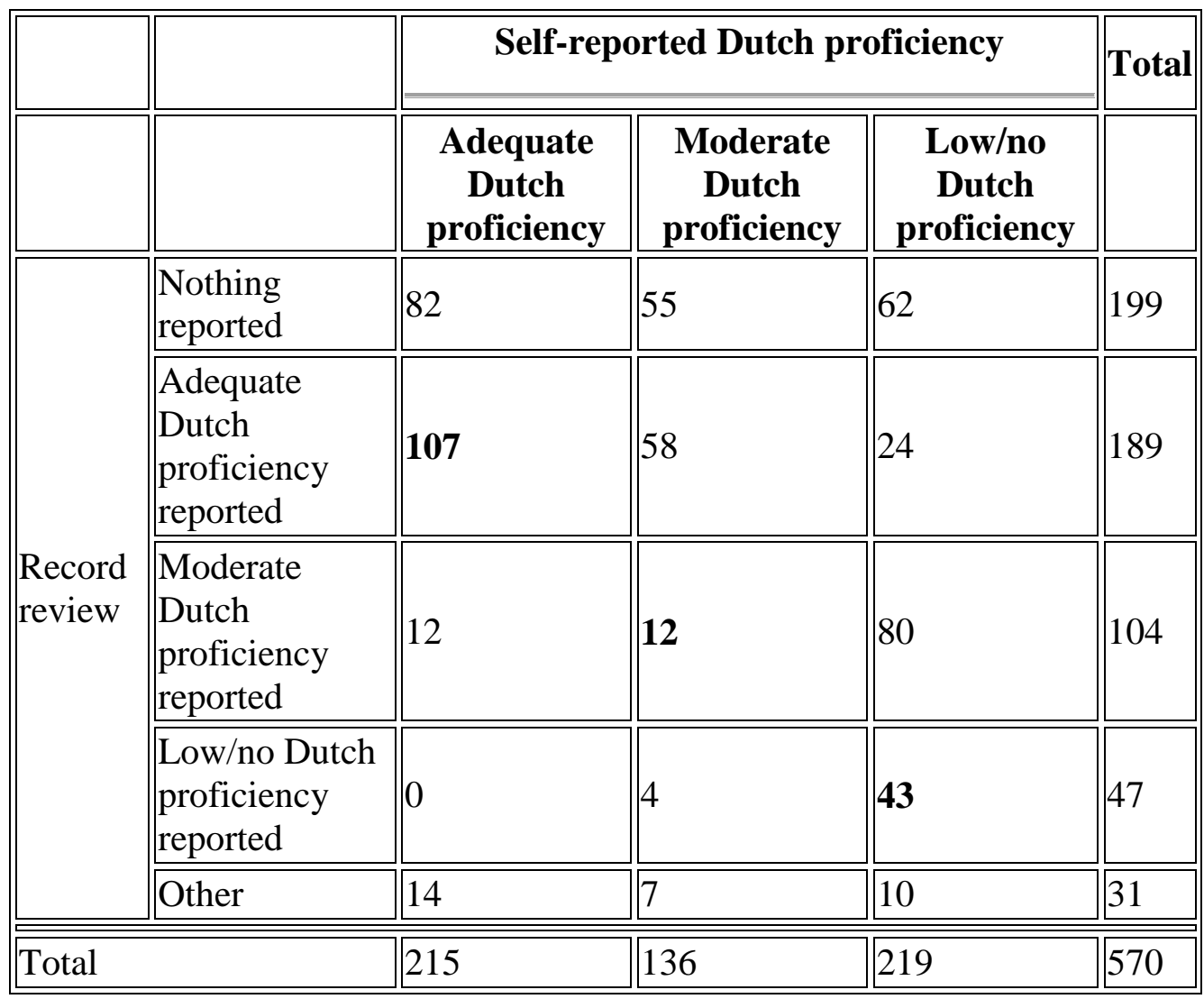

Numbers in boxes where self-reported- and record-reported proficiency match are printed in bold.

$\chi^{2}$ test significance 0.00 . 
Rosse, F. van, Bruijne, M. de, Suurmond, J., Essink-Bot, M.L., Wagner, C. Language barriers and patient safety risks in hospital care: a mixed methods study. International Journal of Nursing Studies: 2015

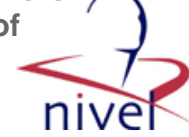

Fig. 1. Flow chart of data collection.

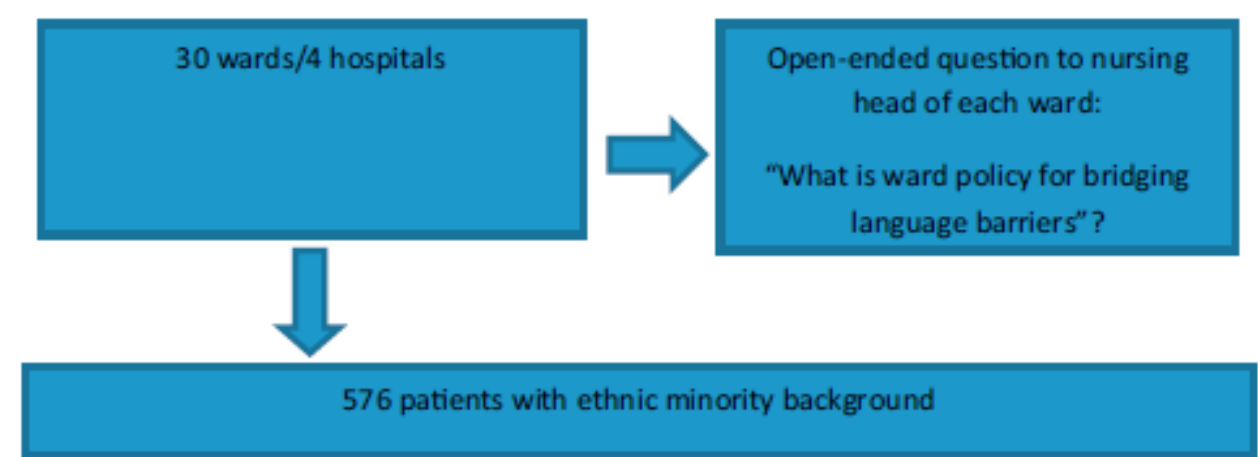

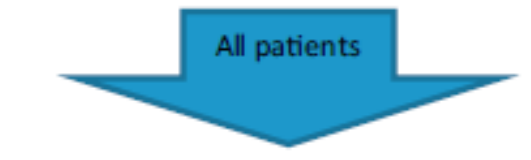

DURING HOSPITALIZATION

1. Survey question: patients ranked their proficiency in understanding, speaking, reading, and writing the Dutch language (classified as not at all, a little, moderately, adequate)

\section{AFTER DISCHARGE}

2. Record review:

a. Language barrier reported in record?

b. If yes: Where? Specific language reported?

c. If yes: Bridging of language barrier reported?

d. If yes: How was language barrier bridged?

e. Open text field for comments on language barrier

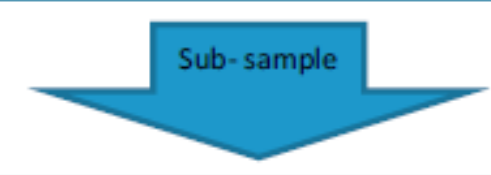

17 admissions of patients with inadequate Dutch proficiency.

1. Thorough document analysis of patient record (patient safety risks, ways of reporting language barrier)

2. Interviews with care providers $(\mathrm{N}=7)$

3. Interviews with patients and/or relatives $(\mathrm{N}=5)$ 
Supplementary file - Table "What is the ward-policy regarding the brigde of language barriers?"

All named policies are indicated with $\mathrm{X}$, the "main"/'first choice" policy, when mentioned, is printed bold.

Non-response: 7 (5 non-surgical wards, 2 surgical wards)

Surgical wards: Including Orthopaedic surgery; non-surgical wards: internal medicine, cardiology, pulmonology, and neurology.

\begin{tabular}{|c|c|c|c|c|c|c|}
\hline & $\begin{array}{l}\text { "Hand } \\
\text { \& feet" }\end{array}$ & $\begin{array}{l}\text { Family } \\
\text { members }\end{array}$ & $\begin{array}{l}\text { Bilingual } \\
\text { personnel }\end{array}$ & $\begin{array}{l}\text { Professional } \\
\text { Interpreter }\end{array}$ & Other & Extra explanations \\
\hline \multicolumn{7}{|l|}{ Surgical wards } \\
\hline 1 & $x$ & $x$ & & $x$ & & $\begin{array}{l}\text { Professional interpreters for bad news or important consulations when } \\
\text { family not available. }\end{array}$ \\
\hline 2 & & $x$ & $x$ & $x$ & & \\
\hline 3 & & & & $x$ & & \\
\hline 4 & & $\mathbf{x}$ & & & & \\
\hline 5 & & $x$ & $x$ & $x$ & & \\
\hline 6 & $x$ & $x$ & $x$ & $x$ & $x$ & Other = Google translate app \\
\hline 7 & & $x$ & & $x$ & & \\
\hline 8 & & $\mathrm{X}$ & $x$ & $\mathbf{x}$ & & This ward indicated the policy is interpreter, but practice is family/personell \\
\hline \multicolumn{7}{|c|}{ Non-surgical wards } \\
\hline 1 & & $\mathbf{x}$ & $\mathbf{x}$ & $\mathrm{X}$ & & \\
\hline 2 & & & & $\mathbf{x}$ & & \\
\hline 3 & & $\mathrm{X}$ & $\mathbf{X}$ & $\mathrm{X}$ & & \\
\hline 4 & & $\mathbf{x}$ & & $\mathrm{X}$ & & \\
\hline 5 & & $\mathrm{x}$ & & $\mathrm{X}$ & $\mathrm{x}$ & Other = A paper with translations of most important sentences \\
\hline 6 & & $\mathrm{x}$ & & $\mathbf{x}$ & $\mathrm{x}$ & Other =A box with various translated materials \\
\hline 7 & & $\mathrm{X}$ & $\mathrm{X}$ & $\mathrm{X}$ & & \\
\hline 8 & & $\mathbf{x}$ & $\mathbf{x}$ & $\mathrm{X}$ & & \\
\hline 9 & & $\mathbf{X}$ & & $\mathrm{X}$ & & \\
\hline 10 & & $\mathrm{X}$ & & $\mathrm{X}$ & & \\
\hline 11 & & $\mathbf{x}$ & $\mathbf{X}$ & $\mathrm{X}$ & & \\
\hline 12 & & & & $\mathrm{X}$ & $\mathrm{X}$ & Other = Special consulent \\
\hline 13 & & $\mathrm{X}$ & & $\mathrm{X}$ & & Policy: For intake: Family members, for bad news: Professional interpreter \\
\hline 14 & $\mathrm{x}$ & $\mathrm{X}$ & $\mathrm{X}$ & $\mathrm{x}$ & & $\begin{array}{l}\text { Policy: Daily practice: Hand and feet, Explanations: Family or bilingual } \\
\text { personell, Important consultations: Professional interpreter }\end{array}$ \\
\hline 15 & & $\mathrm{X}$ & & $\mathrm{X}$ & & Professional interprether when "necessary" \\
\hline TOTAL named & 3 & 20 & 10 & 22 & 4 & \\
\hline TOTAL main & 1 & 9 & 6 & 4 & 0 & \\
\hline
\end{tabular}

